\title{
RUMO A UMA INTERSUBJETIVIDADE CRESCENTE: DEVIRES DE UM PERCURSO
}

\author{
Brenda Luana Schereiner ${ }^{1}$ \\ Elizabeth Medeiros Pacheco ${ }^{2}$ \\ Renato Santanna Barbosa Meira ${ }^{3}$
}

\begin{abstract}
Resumo: $O$ texto que aqui dispomos apresenta duas narrativas em primeira pessoa, como reverberação do encontro promovido pela pesquisa $O$ corpo sem álibi, realizada pelo Departamento de Psicologia da UFF Campos dos Goytacazes, entre cinco educadores articulados pela aposta comum na transdisciplinaridade como regime da educação no contemporâneo. Através de oficinas, filmes e rodas de conversa, questionamos o modo como as resistências aos métodos escolarizados da educação são tomados como incapacidade, desvio ou delinquência, levando crianças e jovens ao diagnóstico de 'inadaptados'. Assumindo outro olhar, crítico-clínico, tomamos tais resistências como efeitos-sujeito analisadores da educação normatizante, e nos implicamos no desafio de produzir outros gestos, que acolham sua diversidade e os aceite e positive como 'Inadaptáveis'.
\end{abstract}

Palavras-chave: afetos; educação; encontro; experiência; resistência.

\section{TOWARDS AN INCREASING INTERSUBJECTIVITY The becoming of a journey}

\begin{abstract}
The text that we have here presents two narratives in first person, as a reverberation of the meeting promoted by the research The body without alibi, carried out by the Department of Psychology at UFF Campos among five educators articulated by the common bet on transdisciplinarity as a regime of education in the contemporary. Through workshops, films and conversation circles, we question the way in which resistance to school-based methods of education is seen as disability, deviation or delinquency, leading children and young people to the diagnosis of 'unsuitable'. Assuming another look, critical-clinical, we take such resistances as effects-subject analyzers of normatizing education, and we imply the challenge of producing other gestures, which welcome their diversity and accept them and Positive as 'Unadapted'.
\end{abstract}

Keywords: affections; education; encounter; experience; resistance.

\footnotetext{
${ }_{1}^{1}$ Graduanda de Psicologia - UFF Campos dos Goytacazes. E-mail: federicibrenda@gmail.com.

2 Doutora e Mestra em Psicologia. Professora Assistente - Departamento de Psicologia - Universidade Federal Fluminense (UFF Campos dos Goytacazes). E-mail: elizabethmp@id.uff.br.

${ }^{3}$ Graduando de Psicologia - UFF Campos dos Goytacazes. E-mail: renatomeira@id.uff.br
} 

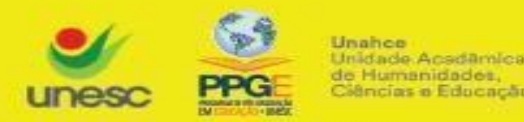

Criar Educação, Criciúma, v. 9, № 3, ago/dez. 2020 - PPGE - UNESC - ISSN 2317-2452

\section{No regime intensivo dos corpos}

A meta não é mais conhecer o mundo objetivo sempre melhor, mas conhecer a circunstância, e conhecer-se nela sempre mais em diálogo com os outros que estão nela comigo.

Vilém Flusser

Escolhemos escrever este artigo, a três vozes, para compartilhar nossa experiência do encontro 'Os Inadaptáveis', realizado em 2019, entre 30 de setembro e 01 de outubro, no campus da Universidade Federal Fluminense em Campos dos Goytacazes onde temos garantido a vigência do projeto de pesquisa 'O corpo sem álibi' desde 2014, junto ao Departamento de Psicologia, com os alunos bolsistas do Programa de Assistência Estudantil - PROAES, e sempre aberto aos alunos interessados em comparecer às nossas experimentações do corpo, rumo à expressividade dos gestos. Partimos da noção ética de Espinosa (DELEUZE, 2002) segundo a qual não sabemos o que pode um corpo quando desobrigado de seus hábitos.

Esta pesquisa nos implica na investigação de nossos hábitos, não para encenálos, mas para nos despojarmos deles de modo a nos abrirmos aos devires dos corpos. Isso implica em encontrarmos uns nos outros, em nossos corpos, as inscrições corporais que nossa história nos faz portar. Mas, se esse processo nos remete inevitavelmente às surpresas do que se mostra no que vemos, o que nos interessa ainda mais é poder encontrar os signos "do que estamos em vias de nos tornar" (VAZ, 1997). Isso nos assusta porque nos remete às sombras do que, contemporâneo a nós, indica a estranheza das nossas operações expressivas; não somos donos de nossa causalidade interna, nem também de nossa expressividade, mas sim efeitos-sujeito de uma experiência sempre compartilhada.

O programa deste encontro 'Os Inadaptáveis' contemplava a intercessão de cada pesquisa entre cinco camadas de intercessão:

Sophie Fahri nos provocava a atravessar nossos corpos do hábito para atingir os corpos invisíveis na dimensão espacializante dos afetos, considerando que os afetos 
também fazem arquiteturas - e isto nos mostra as cidades com essa arquitetura do medo que encerra os espaços do urbano contemporâneo. Foi estranho estar naquela sala onde também temos aulas, e sair do lugar de comportados ouvintes, para o qual éramos diariamente treinados como alunos, para entrar em um espaço sensível aonde íamos, através dos movimentos de nossos corpos, despertando lugares afetivos que costumamos esquecer quando entramos no automatismo derivado da experiência com a instituição escolar e seus procedimentos educacionais, de cujo poder (quase) ninguém escapa.

Porém esta transmutação será necessária: esta a revolução que precisamos fazer, um verdadeiro revirão, ou seja, transversalizar as experiências constituindo um campo problemático e tornar questão o que poderia restar, apenas, como queixa ou ressentimento.

Tal análise veio motivada pelas intervenções de Fernanda Rigue, e sua genealogia da compulsoriedade escolar, instigando a pesquisa das relações de força, saber e poder e sua engrenagem escolarizante no Brasil.

Guilherme Corrêa, químico e professor voltado para a formação de educadores no ensino de ciências na interface educação/política/arte, dobrou o sentido das questões presentes nas vidas do contemporâneo urbano atual, tal como drogas e sexualidade quase sempre concorrentes indissociáveis, e propos oficinas para o ensino de ciências, fazendo valer o caráter lúdico e coletivo das experiências que viram aprendizagem, algo muito diferente da ensinagem instrutivista que, há décadas, vem contribuindo para o aumento da evasão escolar.

Elizabeth Pacheco, estendeu a roda de conversa acerca do desejo, insistindo na dimensão clínica da escuta da criança sobrevivente em cada um, para podermos ainda crer no mundo.

Pedro Almeida trouxe sua escuta intensiva no Acompanhamento Terapêutico de autistas, indagando o corpo a corpo destes gestos, e nos presenteou com um video com seu paciente autista numa residência terapêutica, ponto à prova, através das imagens, 0 
Criar Educação, Criciúma, v. 9, ํㅡ 3, ago/dez. 2020 - PPGE - UNESC - ISSN 2317-2452

conceito de 'linhas de errancia' que Fernand Deligny constitui a partir da criação de mapas dos gestos expressos pelas crianças autistas, com quem ele conviveu por mais de 10 anos, como pudemos depois assistir pela exibição do filme - O Mínimo Gesto (Le moindre geste,1971).

Nesse encontro percebemos o sentido forte da palavra Inadaptável que nos levou a perguntar: Se não podemos adaptá-los às normas, então como inventar um modo, uma ética, para conviver os eles? Como reinventar nossos modos de ver, de sentir e saber, a partir daqueles que são Inadaptáveis?

Entre nós, participantes e organizadores do referido encontro, arquitetos, químicos, psicólogos, educadores, estudantes e professores, a certeza de que diante do diagnóstico de 'delinquente' ou 'inadaptado', priorizaríamos sempre extrair a potência política de resistência na constituição de linhas de fuga que, cada criança ou adolescente, buscando escapar do mundo das coações, traça a seu modo, fazendo o mundo fugir (DELEUZE; PARNET, 1998). E isto, afinal, é também criação, invenção de possíveis.

Este o motivo de deslocarmos o enquadre normopatologizante do diagnóstico de Inadaptados, aplicado a todo aquele que não se adequa às expectativas institucionais, para uma aposta desejante dos que são e sempre serão Inadaptáveis. Esta foi uma escolha que nos conectou a ponto de inventarmos este encontro de dois dias, que viraram três, pois incluiam as viagens entre Rio de Janeiro, Santa Maria, Niteroi e Campos dos Goytacazes. Mas as distâncias não são só geometrias, são muito mais, são afetos, desejos, afinidades.

Na escuta de Flusser (2014), em sua astuta leitura da crise do contemporâneo e suas inevitáveis mutações nos gestos, entendemos a torção que se opera sobre o sentido de conhecimento e sua inevitável idéia de progresso. Diferindo de desejo de um crescente poder de manipulação sobre o mundo objetivo, as afinidades entre nossas pesquisas derivam de que os problemas vitais que se precipitam sobre nós exigem pesquisa transdisciplinar, porque visam nossa implicação na inventividade de novos modos de existência, fazendo com que o gesto de pesquisar "volte a ser gesto de vida" 

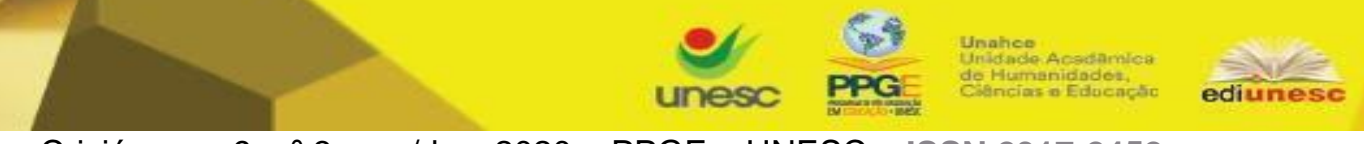

Criar Educação, Criciúma, v. 9, ㄲo 3, ago/dez. 2020 - PPGE - UNESC - ISSN 2317-2452 (FLUSSER, 2014).

Durante todo esse movimento de indagações que compartilhamos entre nós neste encontro, no qual mais de 40 pessoas, entre oficinas e conversas, faziam pulsar experiências que reverberavam para alguns em memórias do vivido e, para outras, no inédito do jamais vivido, nem em família, nem entre amigos - chegamos à certeza de que a língua dos contratos jamais abolirá a língua dos contatos. Os contatos alegres aumentam nossa imunidade e nossa vontade de mundo.

Então, nós que estivemos juntos nestes dois-três dias, precisávamos de registros que ativassem por muito tempo a certeza do que fiamos juntos. De modo a poder garantir sua revivência a cada vez que nos sentirmos ameaçados pelo juízo moral sobre nossas brincadeiras, nossas magias, nossas itinerrâncias. Não viemos ao mundo para nos conformar, e sim, para inventar outros mundos, sem governo e sem juízo, tal como o fazem as crianças em estado de dedicação atenta quando estão brincando. $O$ jogo abre a ilusão (in ludens) e convoca um estado de atenção interessada que produz conhecimento, ou seja, nascimento simultâneo de si e de mundo.

Figura 1: Oficina 'As cores da Sombra'.

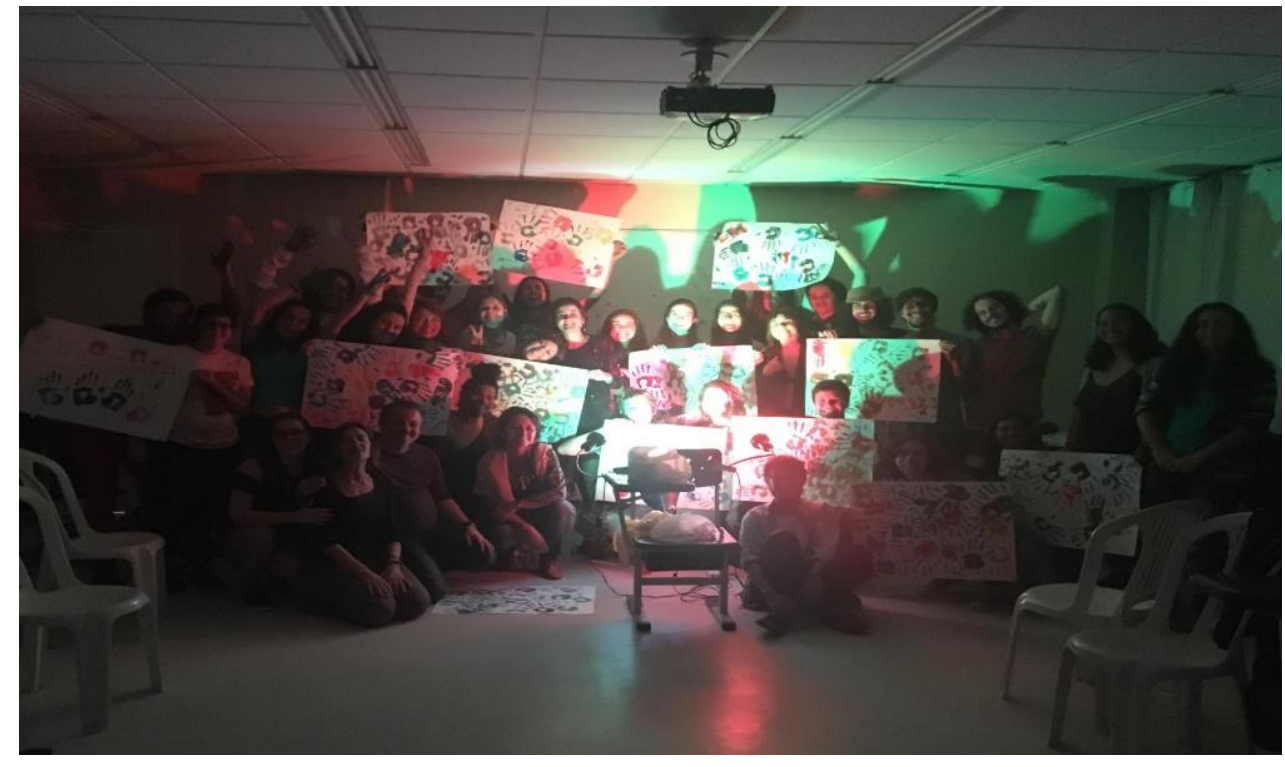

Fonte: Acervo dos autores (2019). 


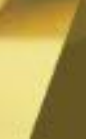
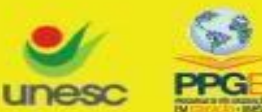

Unahoe:
Unidade Acodamicat
do Humanidiodos:

PPGE

ediunesc

Criar Educação, Criciúma, v. 9, nº 3, ago/dez. 2020 - PPGE - UNESC - ISSN 2317-2452

\section{Escrevivendo a experiência}

Segundo o discurso da ciência — ou segundo certo discurso da ciência — o saber é um enunciado; na escritura, ele é uma enunciação. $O$ enunciado, objeto habitual da lingüística, é dado como o produto de uma ausência do enunciador. A enunciação, por sua vez, expondo o lugar e a energia do sujeito, quiçá sua falta (que não é sua ausência), visa o próprio real da linguagem; ela reconhece que a língua é um imenso halo de implicações, de efeitos, de repercussões, de voltas, de rodeios, de redentes; ela assume o fazer ouvir um sujeito ao mesmo tempo insistente e insituável, desconhecido e no entanto reconhecido segundo uma inquietante familiaridade: as palavras não são mais concebidas ilusoriamente como simples instrumentos, são lançadas como projeções, explosões, vibrações, maquinarias, sabores: a escritura faz do saber uma festa. $O$ paradigma que aqui proponho não segue a partilha das funções; não visa a colocar de um lado os cientistas, os pesquisadores, e de outro os escritores, os ensaístas; ele sugere, pelo contrário, que a escritura se encontra em toda parte onde as palavras têm sabor (saber e sabor têm, em latim, a mesma etimologia) (BARTHES, 1980, p. 20).

Roland Barthes em seu livro 'Aula (1980) comenta o lugar de enunciação da escritura, mais que um lugar de enunciado. Deste modo escolho trazer as narrativas de dois participantes deste encontro como maneiras de escreviver o que se passou pois, talvez, esse neologismo permita a intersecção entre estas ações, indissociáveis quando situamos em narrativa de 1a pessoa a escrita da experiência, entre o vívido e o vivido, numa narrativa impregnada de sujeito e de sabor.

O atravessamento que vivemos todos, participantes e coordenadores das oficinas, nos permitiu fazer das palestras uma experiência de troca de vivências e relatos espontâneos. Muito gratificante sentir a interlocução fluir entre quase 40 pessoas. Mas a questão que mais motivou a discussão, passada uma primeira fase de silêncio e estranhamento, foi a dificuldade de compreender a valoração que dávamos ao sentido de inadaptável. Desta surpresa resultaram duas escritas que apresentamos aqui - uma de maravilhamento, pelas lentes da química, na surpresa narrada por Brenda, graduanda em Psicologia com estágio em escola municipal de Campos que relata sua compreensão da diferença entre instrução e educação, a partir da oficina das cores e das sombras; 


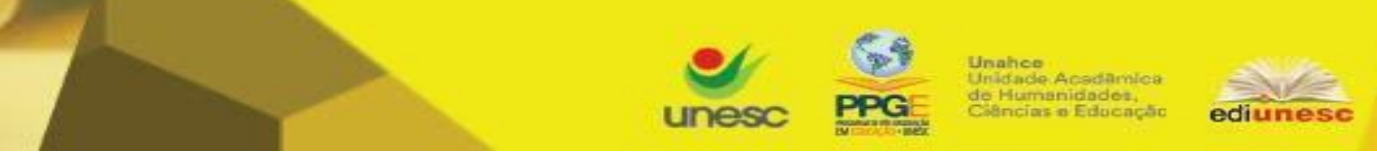

Criar Educação, Criciúma, v. 9, ํㅡ 3, ago/dez. 2020 - PPGE - UNESC - ISSN 2317-2452

outra escrita, resultado da vivência de Renato, também graduando em Psicologia com estágio na Unidade de Acolhimento Infanto-juvenil e Centro de Atenção Psicossocial Infantil, que teve com esta oficina um reencontro com seu percurso de vida e, afetado de memórias, ele inventa, fabula, escrevivendo um conto: um bando e um anômalo. Muitas vezes "o real precisa ser ficcionado para ser pensado" (RANCIÈRE, 2005).

Escreviver então é um verbo, um neologismo, que expressa um modo da ação com que Brenda, pelas lentes da química, e Renato pela fabulação de um conto, um bando e um anômalo tornaram matéria expressiva o quanto foram afetados pela experiência deste encontro.

\section{Pelas lentes da química}

O gesto de escrever é uma forma de pensar-se Vilem Flusser

A dificuldade em escrever os afetos a partir da experiência, em um artigo científico, é desafiadora e me colocou em situação de desconforto a ponto de ficar por horas em frente a uma página em branco, sem saber o que e como escrever. A partir disso me pergunto quais são os espaços para o saber das vivências? Quais potências foram vividas e não foram descritas nos livros científicos? Quais afetos estavam atrelados ao nosso processo de aprendizagem? O que os livros não nos contaram?

O lugar de potência em que me encontro como aluna me atravessa e, a partir dessa reflexão, escrevo minha experiência com o encontro realizado em outubro de 2019 na Universidade Federal Fluminense, chamado 'Os Inadaptáveis'. Apesar da vontade de descrever cada parte que me afetou deste encontro, escolho falar de uma forma geral dos atravessamentos que me trouxeram aprendizados acerca das relações que ali construímos e constituímos, dois verbos quase sinônimos, mas que nesta escrita um vem como forma de conceber algo a partir da criação, e o outro como dar existência sendo parte essencial deste algo. 
Durante o cronograma do encontro, realizaram-se atividades que nos colocavam como sujeitos participativos atuantes daquele cenário, seja no modo oficina, seja nas rodas de conversações; em ambos aprendemos e compartilhamos a partir do que estávamos experimentando naquele momento.

Uma das oficinas ficou de fato marcante em minha memória. Estávamos em 30 ou 40 alunos e o professor de química Guilherme Corrêa, nos convidou a conhecer mais sobre a ótica das cores. As luzes da sala em que estávamos foram apagadas, tampamos janelas e frestas para vedar qualquer luminosidade. E então começou o espetáculo das cores. Cores primárias, cores secundárias. A projeção de luz sobre filtros próprios em superfícies brancas e pretas. O regime de luz incluindo uma oficina de sombras. Depois juntamo-nos em grupos e experimentamos na prática a junção das cores, numa 'bagunça' linda com coloridos de tintas guache. Eram mãos azuis entrelaçando-se com mãos amarelas. Mãos verdes indo ao encontro de mãos vermelhas. Nos lambuzávamos uns aos outros. Brincávamos e aprendíamos sobre aquela química linda das composições de cores e de corpos.

De fato percebi que, anteriormente, eu ainda não havia aprendido sobre as cores. Já havia estudado para passar em provas, mas não havia realmente aprendido. Experimentar a relação entre as cores me levou também a experimentar minha relação afetiva com estas. Ali, naquele espaço de aprendizagem, não havia obrigatoriedade em provar meus conhecimentos, mas sim experimentar os efeitos sobre meus afetos experienciando um processo químico que está presente em todos os espaços de luz dispostos, logo, também um aprendizado que espacializa o mundo e me constitui enquanto sujeito.

'Os Inadaptáveis' fez-se em teatro. Nas 'palestras', que na verdade pareciam mais conversas, todos ali tinham voz e vinham a se tornar atores daquele espaço também experimental. Minhas experiências desse encontro, levarei em minhas memórias, levarei nossos encontros como um grande espetáculo teatral vivido, no qual todos se fizeram atores de uma linda e revolucionária experiência, na minha historia, do que pode a 


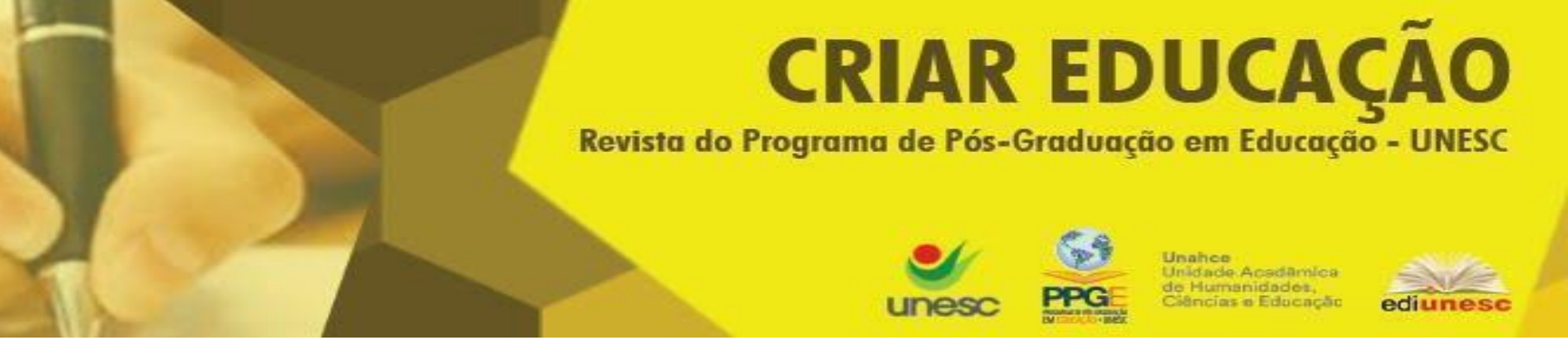

Criar Educação, Criciúma, v. 9, no 3, ago/dez. 2020 - PPGE - UNESC - ISSN 2317-2452

educação quando vivida em regime de jogo, de magia, de invenção.

\section{Um conto, um bando e um anômalo}

O que será que será

O que não tem governo

nem nunca terá,

porque não tem juízo

Chico Buarque - À flor da pele

A situação se intensificou quando passei para a sexta série do antigo segundo grau. Fui estudar numa escola estadual, num lugar muito conhecido por avenidas que se cruzam, fazendo o trânsito fluir para os quatro cantos da cidade. Uma ferrovia corta a cidade, passando no meio do bairro. Lá, havia uma comunidade que costumava ser chamada de Caldeirão do Diabo, situada no final da avenida. O modo como as casas foram construídas pelos próprios moradores formavam um circulo quase fechado. Anos depois, a prefeitura realizou uma obra estendendo a avenida e removendo as casas dos moradores, fazendo os carros passarem pelo meio da comunidade. Além disso, mudou seu nome, mas nós continuávamos chamando de Caldeirão de Diabo.

Quando criança, ouvíamos os vizinhos dizerem:

- Essa escola é uma bagunça, eles dão muita liberdade para esses alunos, escute só a gritaria dessas crianças! É o tempo todo, os professores não tem autoridade! Pelo amor de Deus! É por isso que o Brasil não vai para frente!

Formamos um bando em pouco tempo de convívio das aulas e logo percebi que as 'bagunças', ou nossas brincadeiras, eram mais interessantes, significativas e afetivas, do que qualquer outra coisa ali dentro. Mas o que mais gostávamos de fazer eram as fugas. Era como se, somente no exato momento em que brincávamos de correr entre as árvores, fugir do funcionário, escalar os muros, passar entre as cercas de arame farpado, saltar para fora da escola, é que nós nos sentíamos vivos e livres para explorar a nossa cidade. Mas de tanto repetirmos essa aventura, conseguiram nos proibir e reforçaram a 

segurança dos muros e a vigilância.

Para resolver esse problema decidimos não entrar mais na escola, mas saíamos de nossas casas de segunda à sexta, pontualmente às $12 \mathrm{~h} 45 \mathrm{~min}$, uniformizados e com nossas mochilas, porém desviávamos o caminho para outros lugares maravilhosos, tais como: a casa de fliperama, a obra interrompida de um prédio abandonado, a pista de skate na praça, ou íamos surfar na praia. Essa última aventura era a mais difícil, pois tínhamos que arrumar algum lugar para tomar banho e trocar de roupas, antes de voltar para casa.

Também gostávamos de pegar carona em caminhões ou pequenas caminhonetes percorrendo toda orla da praia com a brisa do mar batendo em nossos rostos sorridentes.

Um de nós era tão rápido que conseguia pegar as frutas nas feiras sem que ninguém percebesse. E quando outro do bando tentava, logo era surpreendido por algum feirante. Outro de nós era muito bom em Surfar, só que em cima dos trens, ficávamos perplexos com sua coragem e seu equilíbrio. Porém, sua relação com o trem entrou em uma linha de abolição terrível e o acontecimento fez com que ele caísse nos trilhos e perdesse as duas pernas. Desde então, ficávamos longe dos trens. O mais forte do bando adorava assistir filmes do Bruce Lee, e se tornou muito bom em brigar com dois ou três ao mesmo tempo, não tinha medo de ninguém, ficávamos impressionados com sua agilidade e foi nomeado líder do bando. O mais belo tinha um rosto angelical e gostava de fazer alguns favores para um senhor. Voltava com os bolsos cheios de dinheiro e gastava tudo com doces em poucas horas. Outro, muito bom em matemática, tinha um dom em negociar com pessoas estranhas que trabalhavam no Porto, logo se tornou nosso contrabandista oficial.

$\mathrm{Na}$ obra de um prédio abandonado atrás da escola tínhamos tudo que precisávamos: revistas de mulheres nuas, um estoque de comida, bebidas, drogas e 0 principal, nenhum adulto por perto. Tratava-se de nosso território existencial e, por vezes, tínhamos de defendê-lo da invasão de outros bandos ou de aumentar nossas forças fazendo algum pacto com outro bando. Ao construirmos um grão de experiência no entre- 
corpos cotidiano, sem álibis, podíamos viver a experiência sensível como um devircriança inventando ambientes intensivos e, portanto, eternos.

Assim, passávamos os dias sem que ninguém nos perturbasse.

Lá, neste espaço potencial, os afetos foram então mudando de natureza, e novamente sentimos algo de intensivo a ponto de nos fazer demorar no tempo. Desse modo a experiência se tornou valiosa, sabemos que não acontece com todos, mas para alguns a magia do encontro aparece, e quando nos damos conta, fomos afetados, talvez felizes sem perceber, e as horas se passaram...

Aprendemos a fumar e começamos a cheirar benzina. O mais franzino, que era também tão pequeno que parecia um pigmeu, conseguia dar grandes saltos, atravessando com muita facilidade os muros mais altos dos quarteirões. Criou um hábito de pixar nos cadernos e depois nas paredes, sua letra era perfeita e por isso tornou-se especialista em falsificar assinaturas de nossos pais. Então íamos até a farmácia do bairro com o seguinte bilhete:

-Senhor farmacêutico, por favor, venda-me 5 litros de benzina.

-Pode entregar ao meu filho, eu me responsabilizo.

-Agradecida. Ass: Sra...

Para além de inalar, nunca soubemos qual era a verdadeira serventia da benzina e quando o farmacêutico nos perguntava o que minha mãe iria fazer com tanta benzina, dizíamos que era para limpar nossos aparelhos eletrônicos. Esse esquema funcionou por um tempo até que, pararam de vender benzina nas farmácias. Esse problema foi resolvido ao migrarmos nosso consumo para cola de sapateiro.

Certo dia uma senhora que mal conhecíamos nos viu alucinados em cima de um caminhão no horário em que deveríamos estar na escola. Consequentemente, contou aos nossos pais, que acabaram por descobrir quase todas as nossas peripécias.

A partir disso, as duas instituições, familiar e escolar, se tornaram insuportáveis. Fomos então proibidos de nos encontrar. Neste momento, porém, havíamos conhecido algumas garotas que aceitaram fingir de nossas namoradas só para nos retirar do castigo. 
Desta forma, nosso bando resistiu.

Rebeldes e desajeitados demais para trabalhar, não conseguíamos permanecer em nenhum emprego. O único lugar aceitável e agradável eram as esquinas e os amigos semelhantes. Mas não demorou muito tempo, até a polícia começar a prender nossos amiguinhos por causa de uma planta proibida.

Meus pais assustados com as palavras de ordem transmitidas pela TV, sobre as drogas e sua relação com o crime, me conduziram com meus 16 anos, para uma 'Comunidade terapêutica', mas que de terapêutica nada tinha. Tratava-se de uma comunidade religiosa, misturada com o regime militar, onde a disciplina, a oração e o trabalho imperavam, e quem não obedecesse era punido. As punições variavam entre cavar buracos com a pá ou retirar o capim do campo com uma enxada. Também perdíamos todo o direito ao lazer.

A partir daí, a intensidade da violência só aumentou. Ao deduzirmos que um jovem é vitima de uma situação e ao forçá-lo a aceitar uma proposta de 'salvação', quando, na verdade esse jovem não é uma vítima e nem muito menos acredita nessa tal salvação, o resultado tem grande chance de ser o aumento da violência.

De mim, lembro que me identificaram com diversos diagnósticos e para cada acontecimento eu me encaixava em algum deles perfeitamente. $E$ assim foram problemáticas as tantas vezes em que me internaram em algumas dessas instituições. Por vezes, quando a crise era grave, exigia uma clínica psiquiátrica. Isto sem contar uma vez em que fui preso no Centro Provisório de Detenção.

Mas o tempo passou. Em 2014 conheci um cursinho comunitário, situado nos fundos de uma Igreja do Valongo, que preparava jovens pretos e jovens de baixa renda para prestarerm exame vestibular, com esperança de entrarem nas universidades. Lá conheci um professor de literatura, que foi um dos responsáveis por despertar em mim o desejo de ler e amar a literatura. Sua experiência com o teatro fazia com que as aulas ficassem maravilhosas. Uma vez chegou chorando na aula e pediu para que fizéssemos um minuto de silêncio em homenagem ao poeta Manoel de Barros que havia falecido 
naquele dia. Ao final de cada aula sorteava livros.

Outro professor, um jovem preto, formado em direito, me ensinou como fazer uma redação crítica. Abordava sempre a questão das lutas de classe e do racismo estrutural. Ambos os professores pareciam uma mistura de feiticeiros com narradores.

Aos sábados passávamos o dia inteiro estudando, eles preparavam um almoço com muito carinho e na parte da tarde tínhamos aulas de política, cultura e cidadania com a professora e seus convidados.

Desde então eu comecei a acreditar na existência de outros(as) professores(as), assim como eles, nas universidades. Despertaram em mim o sonho de entrar na universidade, sonho que até então não existia; e sequer pensava em psicologia. Pareceme que os devires-loucos e caóticos mudaram de natureza, não sei, mas com o tempo o desejo se transformou em questão, aquilo que no início era somente um enigma ou uma missão sem sentido.

As linhas duras das instituições tornaram-se mais flexíveis, criando espaço para desejar, conhecer e aprender a pesquisar.

Eu me apaixonei pelas aulas neste lugar precário e cheio de dificuldades. Quando chovia muito a sala de aula ficava alagada, mas o amor dos(as) professores(as) voluntários(as) era tão genuíno, que estudávamos com os pés em cima das cadeiras. Fiz amigos e amigas maravilhosos.

Constituíamos um outro estilo de bando, juntos ampliávamos nosso espaço de outro modo, muito cinema, teatro, música, filosofia e política. Nossas experiências se transformaram em memórias afetivas. Algum tempo depois, sete de nosso bando ingressaram nas universidades federais. Recentemente procurei saber sobre 0 antigo bando e, com surpresa, cheguei a alguns percursos: o mais rápido, e que roubava as frutas, começou a roubar bicicletas e depois aparelhos de som de carros, entrou para uma quadrilha que fazia duble de carros, foi preso, cumpriu sua sentença e hoje está trabalhando como motorista de aplicativo. O mais belo tornou-se garoto de programa e depois tentou fazer faculdade de turismo, se viciou em crack e foi parar nas ruas, mas 
uma antiga amiga apaixonada o retirou das ruas e pagou uma clínica de reabilitação chamada Vila Serena, localizada no interior de São Paulo. Sobre o mais forte do bando, nada descobri de seu paradeiro. O mais franzino, que pixava muros e falsificava assinaturas, era descendente de japoneses e conseguiu ir para o Japão para trabalhar como webdesigner, casou-se e tem dois filhos - saltou para o outro lado do mundo.

O que era bom com os negócios tornou-se um traficante internacional, enviando cocaína para Europa e remédios tarja preta para um país do Oriente Médio; na utopia viveu suas gloríolas, mas degradou na epopéia: foi preso e assassinado por facções rivais.

O que gostava de surfar em trens, após perder as pernas, se recuperou e virou um atleta de canoa havaiana, conseguiu comprar duas próteses à prova d'água. Hoje é professor de canoa havaiana na Ponta da Praia.

E eu, que estou narrando este conto, posso dizer que me tornei um efeito de todos os encontros que aconteceram nesta vida, e cada vez mais ciente de que:

\begin{abstract}
Ética não é a vida que simplesmente se submete à lei moral, mas a que aceita, irrevogavelmente e sem reservas, pôr-se em jogo nos seus gestos. Mesmo correndo o risco de que, dessa maneira, venham a ser decididas, de uma vez por todas, a sua felicidade e a sua infelicidade (AGAMBEN, 2007, p. 54).
\end{abstract}

\title{
Reverberando Conceitos Situações Cenários
}

Aprender o quê num encontro de dois dias? Trata-se de aprender ou de experimentar? Uma coisa difere da outra como, por quê? Trata-se de ser afetado por experimentações que nos tiram do lugar previsível dos hábitos e nos expõem ao acontecimento. Nestes dias houve uma chuva de conceitos agindo como intercessores. O conceito de irreversibilidade, por exemplo, através da química das misturas, pela composição de ingredientes que não mais poderiam se reconhecer como eram antes da mistura; tornaram-se um efeito irreversível, apenas capaz de sofrer outras mudanças. Jamais voltar ao que eram antes. 


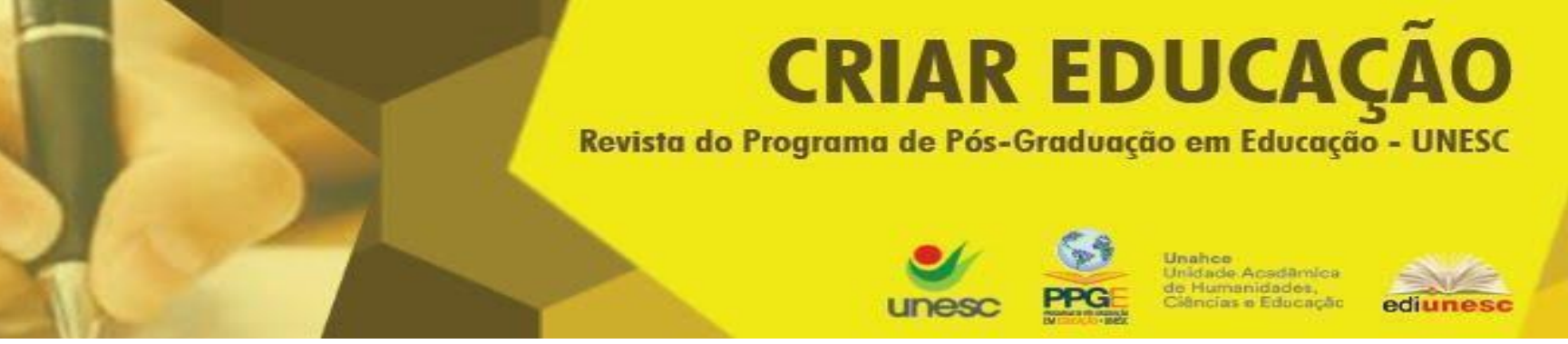

Criar Educação, Criciúma, v. 9, no 3, ago/dez. 2020 - PPGE - UNESC - ISSN 2317-2452

Quanta questão se abre daí.

Por um lado uma situação química, quase mágica, das matérias.

Por outro lado, a dimensão filosofica das escolhas, já que os caminhos não voltam e uma vez tomada uma direção estaremos afetados por tal escolha. Não seremos os mesmos. Isto nos leva a estarmos implicados com o que nos torna o que somos e o que estamos em vias de nos tornar.

Por outro lado a dimensão de devir de uma individuação (SIMONDON, 2005).

Por outro lado a experiência de uma 'ignorância fértil' que instiga a produzir situação; o desconforto excitante de 'não saber' onde isso vai dar, de correr o risco, de produzir a ocasião e daí substancializar o ocasional. Esta uma dimensão também da criação em arte, onde o vazio de sentido apenas mostra o valor, não a utilidade de uma criação.

Aí se encontra a questão da arte para Nietzsche, como potência de extrair do real outros devires, encontrando o paradoxo da potência do falso, tomando a ficção como método para melhor pensar o real, pois é a imagem quem pode restituir ao objeto o que êle perderia para restar apenas útil, apenas objeto. São os gestos, então, quem espacializa o mundo. Na virtualidade de seu corpo-a-corpo, os corpos são o ambiente do mundo.

Outro conceito forte é o conceito de ilusão (in ludens), que o jogo e o brincar ativam. Será no lúdico que a graça das invenções operam. Mas inventar é tomar o que chega como real, se apossar da tradição, traduzir e transduzir, portanto, inventar: in venire - Será preciso que o mundo exista para que eu o invente? Que paradoxo!

Daí surge outro conceito ainda, a dimensão estética que constitui o plano dos corpos enquanto afetabilidade. Todos os corpos, o corpo. As cores como corpo, e no corpo a corpo das cores na diversidade de suas misrturas e geração de outras cores, tons, tonalidades. 'You can play all the tons you are' - sonhou a moça, em inglês mesmo, na noite entre os dois dias do encontro. Talvez sonhasse em língua estrangeira pelo tanto de estranhamento que havia em suas sensações silenciosas. 
Então vivemos juntos, naqueles dois dias, tamanha imersão que, entre aproximadamente 40 pessoas, sentimos toda uma outra atmosfera se constituindo como território, vivenciando as comunicações entre nós a partir de uma outra lógica, a lógica do sensível, a ponto de podermos assistir aos filmes de Deligny com os autistas na fazenda onde ele foi viver o cotidiano entre eles, compartilhando a temporalidade daquelas imagens e com uma disposição de empatia, já bastante distantes da lógica dos contrários entre normais e anormais; inteiros e deficientes; adaptados e inadaptados. Para além dos contrários havíamos produzido a abertura em nós de conviver e contemplar o diverso. Isso não é pouco para 20 horas de convivência.

Engendra-se, então, esse texto ensaiando uma narrativa do que pode esse encontro que reverberou entre nós a alegria do brincar e nos convocou afetos de esperança e teimosia, os mesmos afetos com que Deligny (2018) conclui suas anotações em seu diários de bordo, quando dirigia o Centro de Observação e Triagem (COT-1947), onde recebia os jovens que aguardavam decisão judicial sobre suas vidas. Nesses seus 'diários de bordo' ele escreve acerca dos vagabundos (in) eficazes:

Será preciso, por favor, liberar ao mesmo tempo as crianças e colocá-las junto de educadores de presença leve, provocadores de alegria, sempre prontos a remodelar bolas de argila, vagabundos eficazes maravilhados pela infância (DELIGNY, 2018, p. 130).

\section{REFERÊNCIAS}

AGAMBEN, Giorgio. Profanações. São Paulo: Boitempo, 2007.

BARTHES, Roland. Aula. São Paulo: Editora Cultrix, 1980.

DELEUZE, Gilles. Espinosa. Filosofia prática. São Paulo: Escuta, 2002.

DELEUZE, Gilles; PARNET, Caire. Diálogos. São Paulo: Editora Escuta, 1998.

DELIGNY, Fernand. Os Vagabundos Eficazes: operários artistas revolucionários: educadores. São Paulo: N_1 edições, 2018. 
DIDI-HUBERMAN, Georges. LEVANTES. edições SESC: 2017.

RANCIÈRE, Jacques. A partilha do sensível. São Paulo: Editora 34, 2005.

SIMONDON, Gilbert. Líndividuation à la lumière des notions de forme et d'information. Grenoble: Éditions Jérôme Millon, 2005.

VILÉM, Flusser. Gestos. São Paulo: AnnaBlume, 2014.

VAZ, Paulo. O inconsciente artificial. São Paulo: Unimarco Editora, 1997.

Recebido em junho de 2020.

Aceito em setembro de 2020. 